\title{
Time dependent risk of gastrointestinal complications induced by non-steroidal anti-inflammatory drug use: a consensus statement using a meta-analytic approach
}

\author{
F Richy, O Bruyere, O Ethgen,V Rabenda, G Bouvenot, M Audran, G Herrero-Beaumont, A Moore, \\ R Eliakim, M Haim, J-Y Reginster, on behalf of the WHO Collaborating Centre for Public Health \\ Aspects of Osteoarticular Disorders, Liège, Belgium
}

Ann Rheum Dis 2004;63:759-766. doi: 10.1136/ard.2003.015925

See end of article for authors' affiliations

Correspondence to: Dr F Richy, Santé Publique, Epidémiologie et Economie de la Santé, CHU, Bât B23, B-4000 Sart-Tilman, Belgium, Europe; florent.richy@ulg.ac.be

Accepted 9 January 2004

\begin{abstract}
Objectives: To provide an updated document assessing the global, NSAID-specific, and time dependent risk of gastrointestinal (GI) complications through meta-analyses of high quality studies.

Methods: An exhaustive systematic search was performed. Inclusion criteria were: RCT or controlled study, duration of 5 days at least, inactive control, assessment of minor or major NSAID adverse effects, publication range January 1985 to January 2003. The publications retrieved were assessed during a specifically dedicated WHO meeting including leading experts in all related fields. Statistics were performed conservatively. Meta-regression was performed by regressing NSAID adjusted estimates against study duration categories.

Results: Among RCT data, indolic derivates provided a significantly higher risk of GI complications related to NSAID use than for non-users: $R R=2.25(1.00 ; 5.08)$ than did other compounds: naproxen: $R R=1.83$ (1.25; 2.68); diclofenac: $R R=1.73(1.21 ; 2.46)$; piroxicam: $R R=1.66(1.14 ; 2.44)$; tenoxicam: $R R=1.43$ (0.40; 5.14); meloxicam: $R R=1.24(0.98 ; 1.56)$, and ibuprofen: $R R=1.19(0.93 ; 1.54)$. Indometacin users had a maximum relative risk for complication at 14 days. The other compounds presented a better profile, with a maximum risk at 50 days. Significant additional risk factors included age, dose, and underlying disease. The controlled cohort studies provided higher estimates: $R R=2.22(1.7 ; 2.9)$. Publication bias testing was significant, towards a selective publication of deleterious effects of NSAIDs from small sized studies.

Conclusion: This meta-analysis characterised the "compound" and "time" aspects of the Gl toxicity of non-selective NSAIDs. The risk/benefit ratio of such compounds should thus be carefully and individually evaluated at the start of long term treatment.
\end{abstract}

$\mathrm{N}$ on-steroidal anti-inflammatory drugs (NSAIDs) are widely used for the treatment of pain, fever, and inflammation. The worldwide NSAID market for both occasional and chronic users has been conservatively estimated at over 60 million people, and some NSAIDs (aspirin, naproxen, ibuprofen, etc) are among the most popular over the counter drugs. ${ }^{12}$ Chronic NSAID treatment effectively reduces the symptoms of many painful arthritic syndromes, but induces adverse gastrointestinal (GI) complications, ranging from abdominal discomfort to life threatening GI ulceration, bleeding, and perforation. ${ }^{3}$ Indeed, through their non-specific inhibition of the two cyclo-oxygenase isoenzymes, both aspirin and conventional NSAIDs induce gastroduodenal damage, ${ }^{56}$ and are now considered as a major cause of iatrogenic pathology. ${ }^{7}$ The most common clinical manifestations of NSAID related GI damage to tissue are a combination of gastroduodenal erosions and ulcerations, often called NSAID induced gastropathy, ${ }^{4}$ affecting $25-50 \%$ of chronic NSAID users. NSAID induced gastropathy may limit long term NSAID treatment and causes a significant financial burden to the healthcare system. ${ }^{489}$

In the late 1980s and 1990s, drug related adverse reactions observed with NSAIDs were assessed in epidemiological studies, mostly cross sectional and case controlled. Their results were pooled in several quantitative systematic reviews ${ }^{10-12}$ aiming at clarifying the relationship between
NSAID use and GI complications. They concluded that exposure to NSAIDs resulted in a threefold increase in the risk of perforation, ulcers, or bleeding in comparison with the risk for non-users. Additional risk factors were shown to be an age greater than 60 years, a previous history of GI events, concomitant corticosteroid and anticoagulant use, and the presence of Helicobacter pylori. This latter risk factor has been extensively explored in a recent meta-analysis. ${ }^{12}$ A synergism was found between NSAIDs and $H$ pylori infection in the risk of peptic ulcers, despite the presence of still unknown sources of heterogeneity in this relation. The odds ratio of developing an ulcer when exposed to NSAIDs in the presence of $H$ pylori was evaluated as greater than 2 .

However, despite the highest level of sophistication of these quantitative systematic reviews, the studies included might not be relaying the best level of evidence. As noted by Hawkey, ${ }^{7}$ Bollini et al, ${ }^{9}$ and Gabriel et al, ${ }^{10}$ most of the metaanalyses focused on cross sectional and retrospective trials, but such designs have been shown to induce overestimated results compared with randomised controlled trials (RCTs) and/or controlled longitudinal cohort studies. The reasons are that RCTs provide a more accurate way to control for confounding factors and bias, and the odds ratios in this

Abbreviations: ANOVA, analysis of variance; $\mathrm{Gl}$, gastrointestinal; NSAIDs, non-steroidal anti-inflammatory drugs; RCT, randomised controlled trial; RR, relative risk 
setting are less conservative estimates than relative risk. A meta-analysis of a high quality RCT is thus, according to the Cochrane Collaboration, the best source of medical evidence. Few attempts have been made to characterise the complex time-effect relationship between NSAID intake and GI side effects. The gaps in the available publications reflect the need for further large epidemiological studies examining these important questions. The need for additional research is supported by the widespread use of conventional, nonspecific NSAIDs, despite the better GI safety profile of cyclooxygenase-2 inhibitors or the combination of NSAIDs and prostaglandins or proton pump inhibitors. ${ }^{13}$

Our goal was to provide an updated document accurately assessing the risk of GI complications induced by the most commonly used non-selective NSAIDs and to characterise the relationship between the duration of exposure and the relative risk of GI complications.

\section{METHODS}

An exhaustive search of all potentially appropriate publications was performed, following a predefined protocol. Electronic sources included Medline and Premedline, Biosis Preview, Healthstar, Embase, Cochrane Library of Randomised Controlled Trials, Current Contents, EBM reviews, and the internet. Because all reports are not indexed in these databases, we conducted a hand search of the reference section. The strategy was derived from the sensitive search strategy currently recommended by the Cochrane Collaboration Musculoskeletal Group, and the results were added to those provided by another validated method. ${ }^{14}$

We retrieved any RCT and controlled cohort study assessing the relationship between exposure to NSAIDs and adverse GI events. Seven NSAIDs were individually investigated: indometacin, naproxen, diclofenac, piroxicam, tenoxicam, meloxicam, and ibuprofen. Other compounds

Table 1 RCTs included in the analysis

\begin{tabular}{|c|c|c|c|c|c|c|c|}
\hline Ref & Author & NSAID & Dose & Indication & $\begin{array}{l}\text { Treated group } \\
\text { size }\end{array}$ & $\begin{array}{l}\text { Placebo group } \\
\text { size }\end{array}$ & Outcomes \\
\hline 19 & Laerum et al & Diclofenac & 150 mg/day & Recurrent renal colic & 41 & 39 & Gl-minor \\
\hline 25 & Wahlström et al & Diclofenac & $150 \mathrm{mg} /$ day & $\begin{array}{l}\text { Heterotopic ossification after hip } \\
\text { arthroplasty }\end{array}$ & 46 & 50 & Gl system disorders \\
\hline 37 & Laurent et al & Diclofenac & 100 mg/day & Proteinuria in glomerular diseases & 14 & 12 & Gl-minor \\
\hline 43 & Bassotti et al & $\begin{array}{l}\text { Diclofenac } \\
\text { Indometacin }\end{array}$ & $\begin{array}{l}150 \mathrm{mg} / \text { day } \\
150 \mathrm{mg} / \text { day }\end{array}$ & Healthy volunteers & $\begin{array}{l}8 \\
8\end{array}$ & 8 & Gl-minor \\
\hline 27 & Reis et al & Diclofenac & $150 \mathrm{mg} /$ day & $\begin{array}{l}\text { Heterotopic ossification after hip } \\
\text { arthroplasty }\end{array}$ & 90 & 90 & Gl-minor \\
\hline 34 & Schnitzer et al & $\begin{array}{l}\text { Etodolac } \\
\text { Nabumetone }\end{array}$ & $\begin{array}{l}800 \mathrm{mg} / \text { day } \\
1500 \mathrm{mg} / \text { day }\end{array}$ & Knee osteoarthritis & $\begin{array}{l}91 \\
89\end{array}$ & 90 & Gl-minor \\
\hline 40 & Laine et al & $\begin{array}{l}\text { Etodolac } \\
\text { Naproxen }\end{array}$ & $400 \mathrm{mg}$ bid & Gastrointestinal tolerability & 18 & 16 & Gl-major \\
\hline 22 & Hoikka et al & Flurbiprofen & 200 mg/day & $\begin{array}{l}\text { Heterotopic ossification after hip } \\
\text { arthroplasty }\end{array}$ & 34 & 34 & Gl-minor \\
\hline 30 & Elmstedt et al & Ibuprofen & $1200 \mathrm{mg} /$ day & $\begin{array}{l}\text { Heterotopic ossification after hip } \\
\text { arthroplasty }\end{array}$ & 21 & 22 & Gl-minor \\
\hline 45 & Langman et al & $\begin{array}{l}\text { Ibuprofen } \\
\text { Diclofenac } \\
\text { Ibuprofen } \\
\text { Diclofenac }\end{array}$ & $\begin{array}{l}2400 \mathrm{mg} / \text { day } \\
150 \mathrm{mg} / \text { day }\end{array}$ & Osteoarthritis & 1564 & 514 & Gl system disorders \\
\hline 41 & Persson et al & Ibuprofen & 1200 mg/day & $\begin{array}{l}\text { Heterotopic ossification after hip } \\
\text { arthroplasty }\end{array}$ & 48 & 47 & Gl-minor \\
\hline 48 & Doyle et al & Ibuprofen & $1200 \mathrm{mg} /$ day & Gastrointestinal tolerability & 833 & 413 & Gl-minor \\
\hline 26 & Schmidt et al & Indometacin & 75 mg/day & $\begin{array}{l}\text { Heterotopic ossification after hip } \\
\text { arthroplasty }\end{array}$ & 102 & 99 & Gl system disorders \\
\hline 20 & Kjaersgaard et al & Indometacin & $75 \mathrm{mg} /$ day & $\begin{array}{l}\text { Heterotopic ossification after hip } \\
\text { arthroplasty }\end{array}$ & 19 & 22 & $\begin{array}{l}\text { Any } G \text { l adverse } \\
\text { event }\end{array}$ \\
\hline 42 & Scott et al & Indometacin & $25 \mathrm{mg} /$ day & Knee osteoarthritis & 202 & 303 & Gl-minor \\
\hline 47 & Eliakim et al & Indometacin & $150 \mathrm{mg} /$ day & Acute musculoskeletal disorders & 65 & 513 & Gl-major \\
\hline 38 & Berry et al & Lornoxicam & $12 \mathrm{mg} /$ day & Knee and hip osteoarthritis & 44 & 42 & Gl-minor \\
\hline 21 & Lemmel et al & Meloxicam & $\begin{array}{l}15 \mathrm{mg} / \text { day } \\
7.5 \mathrm{mg} / \text { day }\end{array}$ & Rheumatoid arthritis & $\begin{array}{l}162 \\
159\end{array}$ & 147 & Gl system disorders \\
\hline \multirow[t]{2}{*}{46} & Yocum et al & Meloxicam & $3.75-15 \mathrm{mg} /$ day & Osteoarthritis & 464 & 157 & $\begin{array}{l}\text { Any Gl adverse } \\
\text { event }\end{array}$ \\
\hline & & Diclofenac & $100 \mathrm{mg} /$ day & & 153 & & \\
\hline \multirow[t]{2}{*}{33} & Lipscomb et al & Meloxicam & $15 \mathrm{mg} /$ day & Gastrointestinal tolerability & 15 & 15 & Gl-minor \\
\hline & & Piroxicam & $20 \mathrm{mg} /$ day & & 14 & & \\
\hline \multirow[t]{2}{*}{35} & Patoia et al & Meloxicam & 15 mg/day & Gastrointestinal tolerability & 13 & 13 & Gl-severe \\
\hline & & Piroxicam & $20 \mathrm{mg} /$ day & & 13 & & \\
\hline 36 & Lund et al & Meloxicam & 15 mg/day & Knee osteoarthritis & 134 & 137 & Gl-minor \\
\hline 44 & Dougados et al & $\begin{array}{l}\text { Meloxicam } \\
\text { Piroxicam }\end{array}$ & $\begin{array}{l}15 / 22.5 \mathrm{mg} / \text { day } \\
20 \mathrm{mg} / \text { day }\end{array}$ & Ankylosing spondylitis & $\begin{array}{l}120 \\
108\end{array}$ & 121 & Gl-major \\
\hline 29 & Simon et al & Naproxen & 500 mg/day & Rheumatoid arthritis & 138 & 101 & GI ulcers \\
\hline 18 & Gebuhr et al & Naproxen & $750 \mathrm{mg} /$ day & $\begin{array}{l}\text { Heterotopic ossification after hip } \\
\text { arthroplasty }\end{array}$ & 28 & 27 & $\mathrm{Gl}$ system disorders \\
\hline 49 & Schiff et al & Naproxen & 1000 mg/day & Knee osteoarthritis & 116 & 116 & Gl-minor \\
\hline 31 & Bono et al & Oxaprozin & $1200 \mathrm{mg} /$ day & Tendinitis and bursitis & 43 & 43 & GI-major \\
\hline 24 & Prupas et al & Tenidap & 40-200 mg/day & Rheumatoid arthritis & 131 & 67 & Gl-minor \\
\hline 23 & Gebuhr et al (2) & Tenoxicam & $40 \mathrm{mg} /$ day & $\begin{array}{l}\text { Heterotopic ossification after hip } \\
\text { arthroplasty }\end{array}$ & 35 & 35 & $\mathrm{Gl}$ system disorders \\
\hline \multirow[t]{2}{*}{28} & Burssens et al & Tenoxicam & $20 \mathrm{mg} /$ day & $\begin{array}{l}\text { Heterotopic ossification after hip } \\
\text { arthroplasty }\end{array}$ & 26 & 29 & Gl-minor \\
\hline & & & $10 \mathrm{mg} /$ day & & 29 & & \\
\hline 50 & Szpalski et al & Tenoxicam & $20 \mathrm{mg} /$ day & Low back pain & 37 & 36 & Gl-minor \\
\hline 39 & Dougados et al (2) & Ximoprofen & $30 \mathrm{mg} /$ day & Ankylosing spondylitis & 50 & 95 & Gl-minor \\
\hline
\end{tabular}


Table 2 Longitudinal controlled cohort studies included in the analysis

\begin{tabular}{|c|c|c|c|c|c|c|c|}
\hline Ref & Author & NSAID & Dose & Indication & $\begin{array}{l}\text { Treated group } \\
\text { size }\end{array}$ & $\begin{array}{l}\text { Control group } \\
\text { size }\end{array}$ & Outcomes \\
\hline 59 & Kurata et al & Any & N/A & $\begin{array}{l}\text { Gastrointestinal bleeding in } \\
\text { patients with dyspepsia }\end{array}$ & 282 & 263 & $\mathrm{Gl}$-major \\
\hline 56 & Allison et al & Any & N/A & Gastrointestinal ulcers & 249 & 464 & Gl-major \\
\hline 51 & Guess et al & Any & N/A & $\begin{array}{l}\text { Fatal upper GI haemorrhage or } \\
\text { perforation }\end{array}$ & $134060 \mathrm{p} / \mathrm{y}$ & $834051 \mathrm{p} / \mathrm{y}$ & $\mathrm{Gl}$-major \\
\hline 60 & McMahon et al & Any & N/A & $\begin{array}{l}\text { Upper GI haemorrhage and } \\
\text { perforation }\end{array}$ & 25700 & 24550 & GI-major \\
\hline 53 & Carson et al & Any & N/A & Upper tract bleeding & 47136 & 44634 & Gl-major \\
\hline 55 & Beardon et al & Any & N/A & Gastrointestinal events & $\begin{array}{l}\text { Events per } 1000 \\
\text { subjects }\end{array}$ & $\begin{array}{l}\text { Events per } 1000 \\
\text { subjects }\end{array}$ & Gl-any \\
\hline 57 & MacDonald et al & Any & N/A & Gastrointestinal toxicity & 52293 & 73792 & $\begin{array}{l}\text { Gl-major } \\
\text { Gl-minor }\end{array}$ \\
\hline 52 & Bloom et al & Any & N/A & $\begin{array}{l}\text { Gastrointestinal toxicity } \\
\text { Cost }\end{array}$ & 33880 & 36200 & $\begin{array}{l}\text { Gl-major } \\
\text { Gl-minor }\end{array}$ \\
\hline 61 & Smalley ef al & Any & N/A & $\begin{array}{l}\text { Incidence of hospitalisations for } \\
\text { peptic ulcer disease in elderly } \\
\text { people }\end{array}$ & $1000 \mathrm{p} / \mathrm{y}$ & $1000 \mathrm{p} / \mathrm{y}$ & Gl-major \\
\hline 58 & Fries et al & Any & N/A & Serious $G$ events & 1694 & 1053 & Gl-major \\
\hline 62 & Garcia Rodriguez et al & Any & N/A & $\begin{array}{l}\text { Hospitalisation for upper } \mathrm{Gl} \\
\text { bleeding }\end{array}$ & 700000 & & Gl-major \\
\hline 63 & Beard et al & Any & N/A & $\begin{array}{l}\text { Hospitalisation for gastro- } \\
\text { oesophageal bleeding }\end{array}$ & $6095000 \mathrm{p} / \mathrm{d}$ & 38006000 & Gl-major \\
\hline 13 & Mamdani et al & Any & N/A & Upper Gl tract bleeding & 5291 & 100000 & Gl-major \\
\hline
\end{tabular}

(etodolac, nabumetone, flurbiprofen, lornoxicam, oxaprozin, tenidap, ximoprofen) were considered as comparators because data available for each compound were too sparse. NSAIDs had to be compared with an inactive control (placebo or non-exposed group). Drugs had to be orally given. In RCTs, both groups had to be matched at inclusion for age, sex, and history of GI events. Treatment duration had to be at least 5 days. The study purposes had to be: safety trials, osteoarticular disorders, or prevention of heterotopic ossification after major orthopaedic surgery. The studies had to be published between January 1985 and January 2003. We focused on English publications or reports

The publications retrieved were discussed for methodological standards and inclusion criteria compatibility during a specifically dedicated WHO meeting, which included leading experts in the fields of rheumatology, gastroenterology, endocrinology, public health, and quantitative epidemiology. Divergences were solved by consensus. Quality scoring was performed using the Jadad score ${ }^{15}$ for RCTs, whereas for longitudinal studies we used a quality scoring algorithm previously defined by our research group. ${ }^{16}$

Data extraction was performed by two independent authors (FR, OB) to ensure accuracy in data encoding. Values from intention to treat analyses were systematically used when available; otherwise we considered per-protocol results. Heterogeneity was assessed before choosing the combination model among the subgroups and in the summary assessment.

The meta-regression process was done in several steps. Firstly, all RCTs were combined to obtain a summary estimate. Thereafter, a subdivision was made according to drug. Finally, the individual estimates were regressed against the respective study durations. Sensitivity analyses were set to explore the confounding effects of age (under versus over 60 years), study purpose (rheumatic diseases versus heterotopic ossification versus tolerability), dose and outcomes, which were categorised in two classes. Minor GI events included abdominal pain, nausea, constipation, diarrhoea, and dyspepsia. Major events included any duodenal, gastric, or intestinal ulcers, bleeding, perforation, hospitalisation, and related death.

The $\alpha$ risks were set at 5\% for association and $10 \%$ for heterogeneity tests. The global and individual estimators were surrounded by their $95 \%$ confidence intervals.
Publication bias was statistically explored by funnel plot drawing (log of the relative risks against their precision, symmetrical if no publication bias is present) and by regressing standard normal deviates of the effects against their precision (no difference from 0 on the $y$ axis if no publication bias is present). ${ }^{17}$ Statistical operations were performed using registered copies of Comprehensive Metaanalysis, version 1.0.25 (Biostat, Englewood NJ 07631, USA), and Statistica 6.0 (Statsoft, France).

\section{RESULTS}

At the end of the bibliographic research, 1893 publications were found. Among them, 527 were selected and reviewed for minimal methodological quality requirements by two authors (FR, OE). After excluding articles solely or predominantly dealing with the tertiary prevention of NSAIDinduced complications by prostaglandins (misoprostol) or other agents, and studies providing insufficient data for subsequent meta-analysis, 32 RCTs on NSAIDs ${ }^{18-31}{ }^{33-50}$ and 13 major cohort studies on NSAIDs ${ }^{13-5155-66}$ were included after review by a specifically dedicated group of experts (see tables 1 and 2). The duration of the included RCTs ranged from 5 days to 1825 days. Among them, 15 studies investigated the anti-inflammatory properties of the drugs in rheumatic diseases, 10 focused on the prevention of heterotopic ossification after major orthopaedic surgery, 5 were GI tolerability trials, 1 was on the improvement of recurrent renal colic, and 1 was on the effect of diclofenac on proteinuria in glomerular diseases. The total number of patients was 5325 receiving active drugs and 3453 receiving placebo in the RCT section. The trials were of good quality according to the classification of Jadad, with a median score of 70\% (range 20-100). Most of the cohort studies were matched for age and sex to enhance comparability between groups, while almost all RCTs assessed homogeneity between groups at inclusion for the major confounding variables. The median daily doses were $1200 \mathrm{mg}$ ibuprofen, $875 \mathrm{mg}$ naproxen, $200 \mathrm{mg}$ flurbiprofen, $30 \mathrm{mg}$ ximoprofen, $1200 \mathrm{mg}$ oxaprozin, $150 \mathrm{mg}$ diclofenac, $800 \mathrm{mg}$ etodolac, $75 \mathrm{mg}$ indometacin, $120 \mathrm{mg}$ tenidap, $15 \mathrm{mg}$ meloxicam, $20 \mathrm{mg}$ tenoxicam and $20 \mathrm{mg}$ piroxicam. 


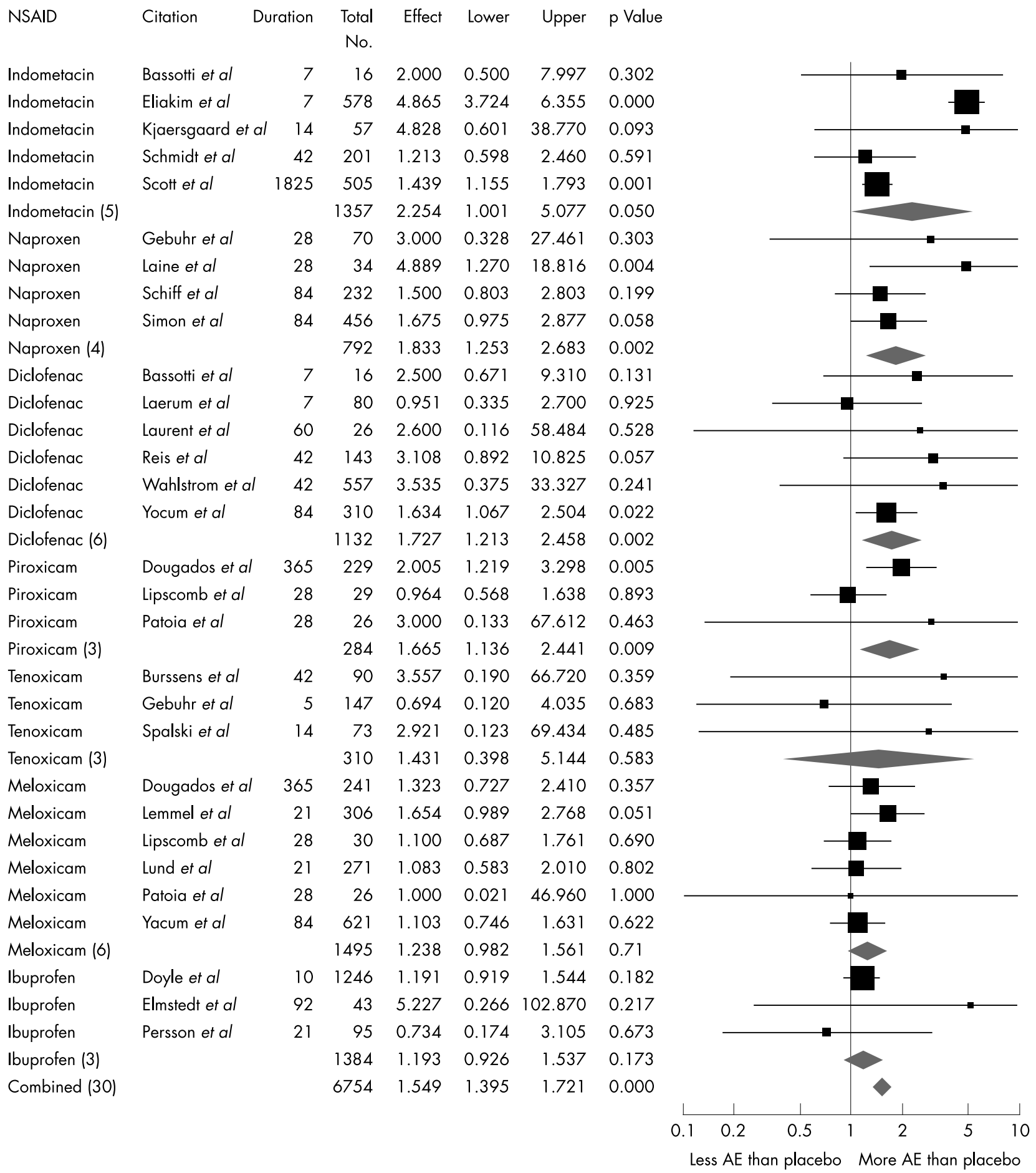

Figure 1 Relative risk of GI complications depending on NSAID (RCT).

\section{Summary of effects}

Among the seven primary NSAIDs investigated, the risk of GI complications due to NSAIDs compared with the risk for non-users was estimated at $1.54(1.4 ; 1.7)$ at a median exposure time of 28 days in the RCTs (fig 1 ). Cohort studies provided a global relative risk of $2.2(1.7 ; 2.9)$ and a median duration of 365 days (fig 4).

\section{Subgroup analyses}

Among the RCT of the seven mainly investigated NSAIDs (fig 1), indometacin provided a significantly higher risk for GI complication: $\mathrm{RR}=2.25$ ( $1.01 ; 5.07)$, followed by naproxen: $\mathrm{RR}=1.83(1.25 ; 2.68)$, diclofenac: $\mathrm{RR}=1.73(1.21$; 2.46), piroxicam: $\mathrm{RR}=1.66 \quad(1.14 ; 2.44)$, tenoxicam: $\mathrm{RR}=1.43(0.40 ; 5.14)$, meloxicam: $\mathrm{RR}=1.24(0.98 ; 1.56)$, and ibuprofen: $R R=1.19(0.93 ; 1.54)$. The other NSAIDs (etodolac, flurbiprofen, lornoxicam, nabumetone, oxaprozin, tenidap, and ximoprofen) provided $\mathrm{RR}=1.64(1.2 ; 2.26)$. The proportion of minor and major GI events studied among those trials was significantly homogeneous among the seven primary NSAIDs investigated (Pearson's $\left.\chi^{2}, \mathrm{p}>0.05\right)$. The meta-regression for non-indometacin NSAIDs, grouped together, provided a duration of treatment of 84 days as threshold for a significant risk of GI effects (fig 2). At seven 


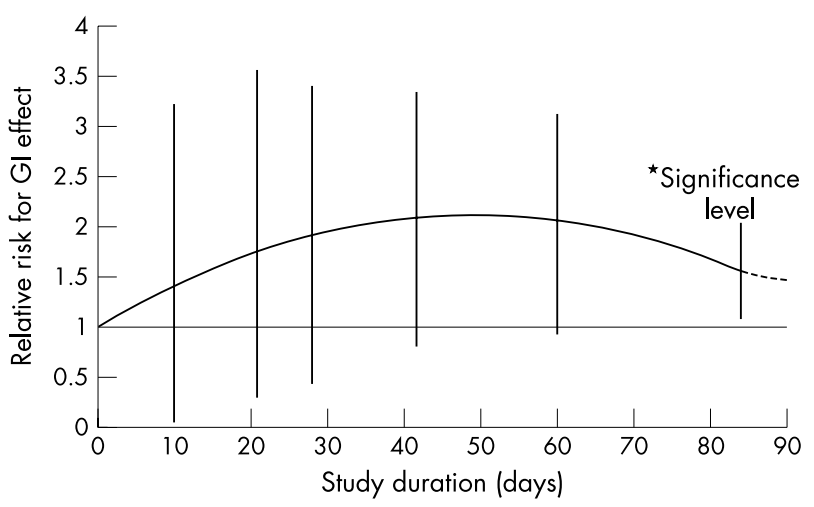

Figure 2 Meta-regression of relative risk against study duration (nonindometacin compounds).

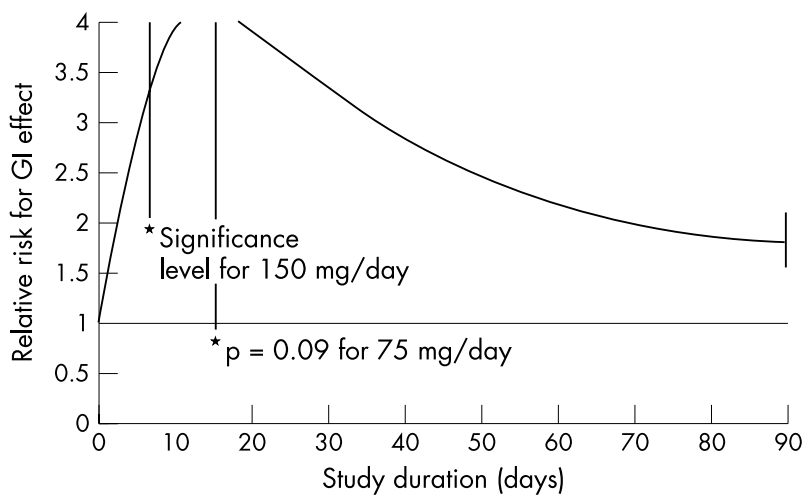

Figure 3 Meta-regression of relative risk against study duration (indometacin).

$\begin{array}{llrrrrr}\text { Citation } & \text { Effect name } & \text { Duration } & \text { Effect } & \text { Lower } & \text { Upper } & \text { p Value } \\ & & & & & & \\ \text { Bloom et al } & \text { Gl-minor } & 90 & 2.464 & 2.202 & 2.757 & 0.000 \\ \text { Bloom et al } & \text { Gl-major } & 90 & 3.271 & 1.398 & 7.657 & 0.004 \\ \text { Carson et al } & \text { Gl-major } & 180 & 1.529 & 1.186 & 1.971 & 0.001 \\ \text { Mamdani et al } & \text { Gl-major } & 365 & 3.846 & 2.283 & 6.479 & 0.000 \\ \text { Kurata et al } & \text { Gl-major } & 365 & 1.632 & 1.017 & 2.618 & 0.039 \\ \text { Guess et al } & \text { Gl-major } & 365 & 3.660 & 2.107 & 6.358 & 0.000 \\ \text { Allison et al } & \text { Gl-major } & 365 & 1.765 & 1.258 & 2.477 & 0.001 \\ \text { Beardon et al } & \text { PUB-women }<60 & 365 & 1.000 & 0.202 & 4.943 & 1.000 \\ \text { Beardon et al } & \text { PUB-men }>60 & 365 & 2.143 & 1.143 & 4.017 & 0.015 \\ \text { Beardon et al } & \text { PUB-women }>60 & 365 & 1.933 & 1.043 & 3.584 & 0.033 \\ \text { Beardon et al } & \text { PUB-men }<60 & 365 & 1.750 & 0.514 & 5.959 & 0.364 \\ \text { Smalley et al } & \text { Gl-major } & 730 & 3.200 & 1.177 & 8.702 & 0.016 \\ \text { McDonald et al } & \text { Gl-major } & 1095 & 1.312 & 1.158 & 1.485 & 0.000 \\ \text { McDonald et al } & \text { Gl-minor } & 1095 & 1.596 & 1.415 & 1.801 & 0.000 \\ \text { McMahon et al } & \text { Gl-major } & 1230 & 2.266 & 1.635 & 3.142 & 0.000 \\ \text { Garcia Rodriguez et al } & \text { Gl-major } & 1460 & 4.837 & 4.260 & 5.493 & 0.000 \\ \text { Fries et al } & \text { Gl-major } & 1460 & 5.594 & 1.701 & 18.395 & 0.001 \\ \text { Beard et al } & \text { Gl-major } & 2190 & 1.391 & 0.930 & 2.080 & 0.106 \\ \text { Combined (18) } & & & 2.218 & 1.699 & 2.895 & 0.000\end{array}$

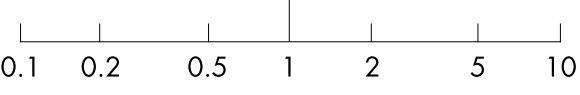

Less $A E$ than placebo More $A E$ than placebo

days of exposure, indometacin at $150 \mathrm{mg}$ daily significantly increased the risk (fig 3) Both categories of compounds displayed a non-linear response of reported risks against study durations.

\section{Sensitivity analyses}

The mean age of patients included in these studies had no significant influence on the reported relative risks: $\mathrm{RR}=1.67$ $(1.02 ; 2.7)$ for studies in patients over 60 and $R R=1.82$ (1.15; 2.87 ) for patients under 60 (analysis of variance (ANOVA), $\mathrm{p}=0.84$ ). The relative risk for GI complications was significantly affected by increasing the daily dose of indometacin (Kendall's $\tau$ test, $\mathrm{p}<0.05$ ), while this covariant remained non-significant for the other compounds. For nonindometacin compounds, we found a significant difference in risk between patients enrolled in tolerability trials: $\mathrm{RR}=1.28$ $(1.04 ; 1.59)$ and patients with osteoarthritis/rheumatoid arthritis or taking NSAIDs after hip arthroplasty: $\mathrm{RR}=1.54$ (1.38; 1.7). The risk for minor events was $\mathrm{RR}=1.35$ (1.14; $1.59)$ and $R R=1.74(1.26 ; 2.41)($ ANOVA-1, $p=0.49)$ for major events. For indometacin trials, insufficient data were present to assess the role of the study purpose. The relative risks for minor and major events were $\mathrm{RR}=1.45(1.18 ; 1.78)$ and $\mathrm{RR}=2.97(1.03 ; 8.5)($ ANOVA $-1, \mathrm{p}<0.01)$.

The cohort studies assessing various NSAIDs (fig 4) reported slightly higher estimates: $R R=2.17 \quad(1.76 ; 2.67)$ for 1 year and below, and RR $=1.45$ (1.19; 1.75) for studies between 2 and 3 years. Four studies assessed the GI adverse effects in cohorts during more than 3 years, and reported $\mathrm{RR}=2.87(1.4 ; 5.9)$. It was noted that, in this analysis, both intra- and intervariability were high (Cochrane's $\mathrm{Q}, \mathrm{p}<0.01$ ), reflecting the lower level of selection of patients and control for bias.

Funnel plots appeared to be asymmetric for the RCT on NSAIDs (fig 5). Indeed more small sized studies reporting a 


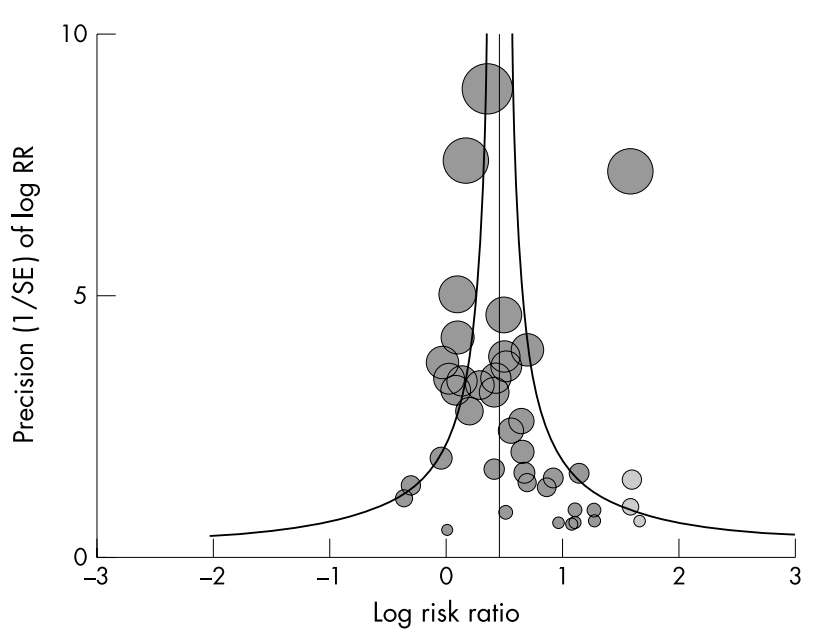

Figure 5 Funnel plot.

marked deleterious effect were retrieved compared with studies reporting no or a less marked adverse effect $($ ratio $=1.29)$. The statistical method confirmed this preliminary inspection $(\mathrm{p}<0.05)$. This means that, in reality, a higher proportion of trials showing lower risks for adverse effects due to NSAIDs have been performed compared with the fraction of published papers showing marked effects.

\section{DISCUSSION}

Throughout the history of NSAIDs we have seen an overall increase in their potency and this has been accompanied, on the whole, by attempts and refinements to improve their tolerability ${ }^{64}$ Despite this trend, however, the classic GI side effects of NSAIDs are just as much a feature of treatment with contemporary drugs as they were with aspirin itself, and in this context it is amazing that aspirin was thought initially to be a better tolerated drug in the stomach than the salicylic acid from which it was derived. Nevertheless, currently, NSAIDs are the best recognised cause of iatrogenic pathology. They have been estimated to cause as many as 16500 deaths a year in the America. ${ }^{65}$ These drugs exhibit a wide range of actions resulting from local and systemic mechanisms, or a combination of both, which contribute to their overall toxicity. ${ }^{66}$

In this quantitative review of English publications, which focused on RCTs and cohort studies, we found deleterious effects of NSAIDs as soon as 1 week after the start of treatment with indometacin. Nevertheless, the magnitude of the risk shown by our results seems to be consistently less alarming than that previously published. ${ }^{10}{ }^{67-73}$ This can be partially explained by the conservative approach we used. For instance, relative risk was used to assess causality instead of an odds ratio. Using odds ratios can lead to overestimated global estimates compared with relative risk, in the analysis of prospective data. ${ }^{74}$ Another possible explanation relates to the fact that we restricted our survey to articles published after 1985. Prior studies might differ because they no longer reflect current practice, and may be of smaller size. We decided to include RCTs and cohort studies. The rationale for this approach was that while we expect the risk estimate to be less biased when derived from RCTs, the populations being studied in such trials are usually highly selected groups and, therefore, are not always fully representative of the patients seen in clinical practice. On the other hand, the analysis performed using non-RCT longitudinal trials provide estimates that may be more representative of daily clinical practice, despite a lack of precision about the NSAIDs used.
Furthermore, there is evidence that case-control studies yield exaggerated estimates of effect compared with cohort studies. ${ }^{75} 76$

In this meta-analysis, we found that indometacin induces a significant risk of GI side effects after less than l week of treatment, whereas other non-specific NSAIDs "required" more than 1 month to induce deleterious effects. Ibuprofen was the safest drug, while naproxen and diclofenac exhibited a higher risk than the investigated oxicams (piroxicam, tenoxicam, and meloxicam), which is consistent with previous findings. ${ }^{5}$

Conflicting results have been reported on the relationship between the risk of GI events and the duration of exposure to NSAIDs. A number of epidemiological studies have suggested that the risk of GI complications is higher at the onset of long term NSAID treatment. ${ }^{13}{ }^{77}$ The findings of this meta-analysis support this claim. The use of meta-regression showed that the maximum risk appeared at 14 days for indometacin, and at 50 days for other NSAIDs. However, prospective experimental studies suggest a steady increase in the rate of GI complications over time. $^{78}$ These differences may be explained by the fact that patients who have not been taking NSAIDs appear to have an increased risk of developing ulcers and clinical events after starting NSAID treatment compared with those who have already been taking NSAIDs. This is related to a selection process of NSAID tolerant patients.

Our data come from studies with various purposes-for example, safety trials versus efficacy trials in patients requiring NSAIDs. Most of the RCTs focused on patients with osteoarticular diseases, mostly osteoarthritis and rheumatoid arthritis (75\%). We found a significant difference in risk between patients without disease $(\mathrm{RR}=1.3, \mathrm{NS})$ and patients with osteoarthritis or rheumatoid arthritis $(R R=1.7$, $\mathrm{p}=0.035$ ). These findings support the claim that the underlying disease requiring NSAID treatment may have a role in the development of GI damage. More studies are needed to assess this point clearly.

This meta-analysis showed a higher risk for major than for minor GI side effects. The explanation is that most of the studies in the first subgroup assessed preclinical erosion of the gastric mucosa as an end point. It has been known for more than 10 years that ulcers defined as breaches in the mucosa may develop within 1 week of regular NSAID use. ${ }^{79}$ Furthermore, the mean age of patients in whom perforation, ulcers, or bleeding were assessed was significantly higher than that of patients in whom minor discomforts were reported (Mann-Whitney $\mathrm{U}, \mathrm{p}=0.04$ ), and they were exposed for a non-significantly longer period to NSAIDs (Mann-Whitney $\mathrm{U}, \mathrm{p}=0.29$ ).

Selective inhibitors of the isoenzyme II of cyclo-oxygenase are now marketed in most North American and European countries for the symptomatic management of osteoarthritis and rheumatoid arthritis. These compounds have, repeatedly, demonstrated that they induce a lower incidence of GI side effects than conventional NSAIDs. ${ }^{80}$ Other studies have also reported a decrease in the GI toxicity of NSAIDs when combined with prostaglandin analogues (misoprostol). ${ }^{81} 82$ However, coxibs and prostaglandin analogues are significantly more expensive than conventional NSAIDs and are not yet widely available to every patient requesting treatment with NSAIDs, which means that the use of non-selective NSAIDs as first line treatment is high and is increasing. ${ }^{83} 84$

\section{CONCLUSION}

The appearance of GI side effects induced by NSAIDs is time dependent but depends less on the drug used. Indometacin at $150 \mathrm{mg}$ daily can exhibit significant deleterious effects as soon as 7 days after initiation of treatment, whereas other NSAIDs, at their recommended therapeutic dose, usually 
induce GI effects after 2-3 months. Depending on the study design, exposure time, compound, and underlying disease, the relative risks of GI adverse reactions compared with untreated controls vary from 1.2 to 5.6. This meta-analysis demonstrates that NSAIDs should be given cautiously to patients requiring long term management of chronic disease. The risk/benefits ratio of such compounds should be carefully and individually evaluated.

\section{Authors' affiliations}

F Richy, O Bruyere, O Ethgen, V Rabenda, J-Y Reginster, Department of Public Health, Epidemiology and Health Economics, University of Liège; WHO Collaborating Centre for Public Health Aspects of Osteoarticular Disorders, Liège, Belgium

G Bouvenot, Department of Internal Medicine and Therapeutics, Centre Hospitalier Régional et Universitaire de Marseille, Hôpital Ste-

Marguerite, Marseille, France

M Audran, Department of Rheumatology, CHRU Faculté d'Angers,

Angers, France

G Herrero-Beaumont, Department of Rheumatology, Madrid, Spain

A Moore, Pain Research, The Churchill, Oxford, UK

R Eliakim, Department of Gastroenterology, Rambam Medical Centre Haifa, Israel

M Haim, Merck \& Co, Paris, France

\section{REFERENCES}

1 Garner A. Adaptation in the pharmaceutical industry, with particular reference to gastrointestinal drugs and diseases. Scand J Gastroenterol Suppl 1992;193:83-9.

2 Lichtenstein DR, Syngal S, Wolfe MM. Nonsteroidal antiinflammatory drugs and the gastrointestinal tract. The double-edged sword. Arthritis Rheum 1995;38:5-18.

3 Cash JM, Klippel JH. Second-line drug therapy for rheumatoid arthritis. N Engl J Med 1994;330:1368-75.

4 Davies NM, Wallace JL. Nonsteroidal anti-inflammatory drug-induced gastrointestinal toxicity: new insights into an old problem. J Gastroenterol 1997;32:127-33.

5 Henry D, Lim LLY, Rodriguez LAG, Gutthann SP, Carson JL, Griffin M, et al. Variability in risk of gastrointestinal complications with individual nonsteroidal anti-inflammatory drugs: results of a collaborative meta-analysis. BMJ 1996;312:1563-6.

6 Tramer MR, Moore RA, Reynolds DJ, McQuay HJ. Quantitative estimation of rare adverse events which follow a biological progression:a new model applied to chronic NSAID use. Pain 2000;85:169-82.

7 Hawkey CJ. NSAIDs toxicity: where are we and how do we go forward? J Rheumatol 2002;29:650-1.

8 Singh G, Triadafilopoulos G. Epidemiology of NSAID induced gastrointestinal complications. J Rheumatol 1999;26(suppl):18-24.

9 Bollini P, Rodriguez LA, Gutthann SP, Walker AM. The impact of research quality and study design on epidemiologic estimates of the effect of nonsteroidal anti-inflammatory drugs on upper gastrointestinal tract disease. Arch Intern Med 1992;152:1289-95.

10 Gabriel SE, Jaakkimainen L, Bombardier C. Risk of serious gastrointestinal complications related to use of nonsteroidal anti-inflammatory drugs. A metaanalysis. Ann Intern Med 1991;115:787-95.

11 Henry D, Lim LL, Rodriguez LA, Gutthann SP, Carson JL, Griffin, et al. Variability in risk of gastrointestinal complications with individual nonsteroidal anti-inflammatory drugs: results of a collaborative meta-analysis. BMJ 1996;312:1563-6.

12 Huang JG, Sridhar S, Hunt R. Role of Helicobacter pylori infection and nonsteroidal anti-inflammatory drugs in peptic-ulcer disease: a meta-analysis. Lancet 2002;359:14-22

13 Mamdani M, Rochon PA, Juurlink DN, Kopp A, Anderson GM, Naglie G, et al. Observational study of upper gastrointestinal haemorrhage in elderly patients given selective cyclo-oxygenase- 2 inhibitors or conventional nonsteroidal anti-inflammatory drugs. BMJ 2002;325:624-7.

14 Dickersin K, Scherer R, Lefebvre C. Identifying the relevant studies for systematic reviews. BMJ 1994;309:1286-91.

15 Jadad AR, Moore RA, Carroll D, Jenkinson C. Assessing the quality of reports of randomized clinical trials: is blinding necessary? Control Clin Trials 1996;17:1-12.

16 Richy F, Bousquet J, Devogelaer JP, Ehrlich G, Meunier P, Peel N, et al on behalf of the WHO Collaborating Center for Public Health Aspects of Osteoarticular Disorders, Liège, Belgium. Inhaled corticosteroids effects on bone in asthmatic and COPD patients: a quantitative systematic review. Osteoporos Int 2003; 14:179-90.

17 Egger M, Smith GD, Schneider M, Minder C. Bias in meta-analysis detected by a simple, graphical test. BMJ 1997;315:629-34.

18 Gebuhr P, Soelberg M, Orsnes T, Wilbek H. Naproxen prevention of heterotopic ossification after hip arthroplasty. Acta Orthop Scand $1991 ; 62: 226-9$

19 Laerum E, Ommundsen OE, Christiansen A, Fagertun HE. Oral diclofenac in the prophylactic treatment of recurrent renal colic. Eur Urol 1995;28:108-11.
20 Kjaersgaard-Andersen P, Nafei A, Teichert G, Schmidt S, Keller J, Lucht U. Indomethacin for prevention of heterotopic ossification. A randomized controlled study in 41 hip arthroplasties. Acta Orthop Scand 1993:64:639-42.

21 Lemmel EM, Bolten W, Burgos-Vargas R, Platt P, Nissila M, Sahlberg D, et al. Efficacy and safety of meloxicam in patients with rheumatoid arthritis. J Rheumatol 1997;24:282-90

22 Hoikka V, Lindholm T, Eskola A. Flurbiprofen inhibits heterotopic bone formation in total hip arthroplasty. Arch Orthop Trauma Surg 1990;109:224-6.

23 Gebuhr P, Sletgard J, Dalsgard J, Soelberg M, Keisu K, Hanninen A, et al. Heterotopic ossification after hip arthroplasty: a randomised double-blind multicenter tenoxicam in 147 hips. Acta Orthop Scand 1996;67:29-32.

24 Prupas HM, Loose LD, Spindler JS, Dietz AJ, Gum OB, Weisman MH. Tenidap in patients with theumatoid arthritis. Scand J Rheumatol 1996;25:345-51.

25 Wahlstrom O, Risto O, Dierf K, Hammerby S. Heterotopic bone formation prevented by diclofenac. Prospective study of 100 hip arthroplasties. Acta Orthop Scand 1991;62:419-21.

26 Schmidt S, Kjaersgaard-Andersen P, Pedersen N, Kristensen S, Perdersen P, Nielsen J. The use of indomethacin to prevent the formation of heterotopic bone after total hip replacement. A randomized, double-blind clinical trial. J Bone Joint Surg Am 1988;70:834-8.

27 Reis H, Kusswetter W, Schellinger T. The suppression of heterotopic ossification after total hip arthroplasty. Int Orthop 1992;16:140-5.

28 Burssens A, Thiery J, Kohl P, Molderez A, Haazen L. Prevention of heterotopic ossification with tenoxicam following total hip arthroplasty: a double-blind, placebo-controlled dose-finding study. Acta Orthop Belg 1995;61:205-1 1 .

29 Simon LS, Weaver AL, Kivitz AJ, Lipsky PE, Hubbard RC, Isakson PC, et al. Anti-inflammatory and upper gastrointestinal effects of celecoxib in rheumatoid arthritis. JAMA 1999;24:1921-8.

30 Elmstedt E, Lindholm T, Nilsson O, Tornkvist H. Effect of ibuprofen on heterotopic ossification after hip replacement. Acta Orthop Scand 1985;56:25-7

31 Bono RF, Finkel S, Goodman HF, Hanna CB, Rabinowitz SR, Sharon E. Oxaprozin in the treatment of patients with tendonitis and bursitis: a comparison with phenylbutasone and placebo. Semin Arthritis Rheum $1986 ; 15: 90-4$

32 Withdrawn

33 Lipscomb GR, Wallis N, Armstrong G, Rees WD. Gastrointestinal tolerability of meloxicam and piroxicam: a double-blind placebo-controlled study. Br J Pharmacol 1998:46:133-7.

34 Schnitzer TJ, Ballard IM, Constantine G, McDonald P. Double-blind, placebocontrolled comparison and efficacy of orally administrated etodolac and nabumetone in patients with osteoarthritis of the knee. Clin Ther 1995; 17:602-12

35 Patoia L, Santucci L, Furno P, Dionisi MS, Dell'Orso S, Romagnolli M, et al. A 4-week, double-blind, parallel-group study to compare the gastrointestinal effects of meloxicam $7.5 \mathrm{mg}$, meloxicam $15 \mathrm{mg}$, piroxicam $20 \mathrm{mg}$ and placebo by means of faecal blood loss, endoscopy and symptom evaluation in healthy volunteers. Br J Rheumatol 1996:35:61-7.

36 Lund B, Distel M, Bluhmki E. A double-blind, randomized, placebo-controlled study of efficacy and tolerance of meloxicam treatment in patients with osteoarthritis of the knee. Scand J Rheumatol 1998;27:32-7.

37 Laurent J, Belghiti D, Bruneau C, Lagrue G. Diclofenac, a nonsteroidal antiinflammatory drug, decreases proteinuria in some glomerular diseases: a controlled study. Am J Nephrol 1987;7:198-202.

38 Berry H, Bird HA, Black C, Freeman AM, Golding DN, Hamilton EB, et al. A double-blind, multicentre, placebo-controlled trial of lornoxicam in patients with osteoarthritis of the hip and knee. Ann Rheum Dis 1992;51:238-42.

39 Dougados M, Nguyen M, Caporal R, Legeais J, Bouxin-Sauzet A, PellegriGuegnault $B$, et al. Ximoprofen in ankylosing spondylitis. Scand J Rheumatol 1994;23:243-8.

40 Laine L, Sloane R, Ferretti M, Cominelli F. A randomized, double-blind comparison of placebo, etodolac, and naproxen on gastrointestinal injury and prostaglandin production. Gastrointest Endosc 1995;42:428-33.

41 Persson PE, Sodemann B, Nilsson OS. Preventive effects of ibuprofen on periarticular heterotopic ossification after total hip arthroplasty. Acta Orthop Scand 1998;69:111-15.

42 Scott DL, Berry H, Capell H, Coppock J, Daymond T, Doyle DV, et al. The longterm effects of non-steroidal anti-inflammatory drugs in osteoarthritis of the knee: a randomized placebo-controlled trial. Rheumatology (Oxford) 2000;39:1095-101

43 Bassotti G, Bucaneve G, Fumo P, Morelli A, Del Favero A. Double-blind, placebo-controlled study of diclofenac sodium and indomethacin on postprandial gastric motility on man. Dig Dis Sci 1998;43:1172-6.

44 Dougados M, Gueguen A, Nakache JP, Velicitat P, Veys EM, Zeidler H, et al. Ankylosing spondylitis: what is the optimum duration of a clinical study? A one year versus a 6 weeks non-steroidal anti-inflammatory drug trial. Rheumatology (Oxford) 1999;38:235-44.

45 Langman MJ, Jensen DM, Watson DJ, Harper SE, Zhao PL, Quan H, et al. Adverse upper gastrointestinal effects of rofecoxib compared with NSAIDs. JAMA 1999;282:1929-33.

46 Yocum D, Fleischmann R, Dalgin P, Caldwell J, Hall D, Roszko P. Safety and efficacy of meloxicam in the treatment of osteoarthritis: a 12-week, doubleblind, placebo-controlled trial. The meloxicam osteoarthritis investigators. Arch Intern Med 2000;160:2947-54.

47 Eliakim R, Ophir M, Rachmilewitz D. Duodenal muscosal injury with nonsteroidal antiinflammatory drugs. J Clin Gastroenterol 1987;9:395-9.

48 Doyle G, Furey E, Berlin R, Cooper S, Jayawardena S, Ashraf E, et al. Gastrointestinal safety and tolerance of ibuprofen at maximum over-thecounter dose. Aliment Pharmacol Ther 1999;13:897-906. 
49 Schiff MH. A comparison of naprelan and naprosyn in the treatment of osteoarthritis of the knee. Am J Orthop 1996;25(suppl):14-20.

50 Szpalski M, Hayez JP. Objective functional assessement of the efficacy of tenoxicam in the treatment of acute low back pain. A double-blind placebocontrolled study. Br J Rheumatol 1994;33:74-8.

51 Guess HA, West R, Strand LM, Helston D, Lydick EG, Bergman U, et al. Fatal upper gastrointestinal hemorrhage or perforation among users and nonusers of nonsteroidal anti-inflammatory drugs in Saskatchewan, Canada 1983. J Clin Epidemiol 1988:41:35-45.

52 Bloom BS. Risk and cost of gastrointestinal side effects associated with nonsteroidal anti-inflammatory drugs. Arch Intern Med 1989;149:1019-22.

53 Carson JL, Strom BL, Soper KA, West SL, Morse ML. The association of nonsteroidal anti-inflammatory drugs with upper gastrointestinal tract bleeding. Arch Intern Med 1987;147:85-8.

54 Withdrawn

55 Beardon PH, Brown SV, McDevitt DG. Gastrointestinal events in patients prescribed non-steroidal anti-inflammatory drugs: a controlled study using record linkage in Tayside. Q J Med 1989;71:497-505.

56 Allison MC, Howatson AG, Torrance CJ, Lee FD, Russell RI. Gastrointestinal damage associated with the use of nonsteroidal anti-inflammatory drugs. N Engl J Med 1992:327:749-54.

57 MacDonald TM, Morant SV, Robinson GC, Shield MJ, McGilchrist MM Murray FE. Association of upper gastrointestinal toxicity of non-steroidal antiinflammatory drugs with continued exposure: cohort study. BMJ 1997:315:1333-7.

58 Fries JF, Williams CA, Bloch DA. Nonsteroidal anti-inflammatory drugassociated gastropathy: incidence and risk factor models. Am J Med 1991;91:213-22.

59 Kurata JH, Nogawa AN, Novitake D. NSAIDs increase risk of gastrointestinal bleeding in primary care patients with dyspepsia. J Fam Pract 1997; 45:227-35

60 McMahon AD, Evans JM, White G, Murray FE, McGilchrist MM, McDevitt DG et al. A cohort study (with re-sampled comparator groups) to measure the association between new NSAID prescribing and upper gastrointestinal hemorrhage and perforation. J Clin Epidemiol 1997;50:351-6.

61 Smalley WE, Ray WA, Daugherty JR, Griffin MR. Nonsteroidal antiinflammatory drugs and the incidence of hospitalizations for peptic ulcer disease in elderly persons. Am J Epidemiol 1995;141:539-45.

62 Garcia Rodriguez LA, Cattaruzzi C, Troncon MG, Agostinis L. Risk of hospitalization for upper gastrointestinal bleeding associated with ketorolac other NSAIDs, calcium antagonists and other antihypertensive drugs. Arch Intern Med 1998;158:33-9.

63 Beard K, Walker AM, Perera DR, Jick H. Nonsteroidal anti-inflammatory drugs and hospitalization for gastroesophageal bleeding in the elderly. Arch Intern Med 1987; 147:1621-3.

64 Flower RJ. Non-steroidal anti-inflammatory drugs: back to the future. Rheumatology (Oxford) 1999;38:693-6.

65 Singh G. Recent considerations in nonsteroidal anti-inflammatory drug gastropathy. Am J Med 1998;105(suppl):31-8s.
66 Wolfe MM, Lichtenstein DR, Singh G. Gastrointestinal toxicity of nonsteroidal antiinflammatory drugs. N Engl J Med 1999;340:341-8.

67 Ofman JJ, Maclean CH, Straus WL, Morton SC, Berger ML, Roth EA, et al. A metaanalysis of severe upper gastrointestinal complications of nonsteroidal anti-inflammatory drugs. J Rheumatol 2002;29:804-12.

68 Watson MC, Brookes ST, Kirwan JR, Faulkner A. Non-aspirin, non-steroidal anti-inflammatory drugs for osteoarthritis of the knee. Cochrane Database of Systematic Reviews 2000:CD000142.

69 Henry D, Lim LL, Rodriguez LA, Gutthann SP, Carson JL, Griffin M, et al. Variability in risk of gastrointestinal complications with individual drugs: results of a collaborative meta-analysis. BMJ 1996;312:1563-6.

70 Kurata JH, Nogawa AN. Meta-analysis of risk factors for peptic ulcer. J Clin Gastroenterol 1997;24:2-17.

71 Derry S, Loke YK. Risk of gastrointestinal haemorrhage with long term use of aspirin: meta-analysis. BMJ 2000;321:1183-7.

72 Neal BC, Rodgers A, Clark T, Gray H, Reid IR, Dunn L, et al. A systematic survey of 13 trials of nonsteroidal anti-inflammatory drugs for the prevention of heterotopic bone formation after major hip surgery. Acta Orthop Scand 2000;71:122-8.

73 Laine L. Approaches to nonsteroidal anti-inflammatory drug use in the highrisk patient. Gastroenterology 2001;120:594-606.

74 Case DL, Kimmick G, Paskett ED, Lohman K, Tucker R. Interpreting measures of treatment effect in cancer clinical trials. Oncologist 2002;7:181-7.

75 Lijmer JG, Mol BW, Heisterkamp S, Bonsel GJ, Prins MH, van der Meulen JH, et al. Empirical evidence of design-related bias in studies of diagnostic tests. JAMA 1999;282:1061-6.

76 Colditz GA, Miller JN, Mosteller F. How study design affects outcomes in comparisons of therapy. Stat Med 1989;8:441-54.

77 Griffin MR, Piper JM, Daugherty JR, Snowden M, Ray WA. Nonsteroidal antiinflammatory drug use and increased risk for peptic ulcer in elderly persons. Ann Intern Med 1991; 114:257-63.

78 Bombardier C, Laine L, Reicin A, Shapiro D, Burgos-Vargas R, Davis B, et al. Comparison of upper intestinal toxicity of rofecoxib and naproxen in patients with rheumatoid arthritis. N Engl J Med 2000;343:1520-8.

79 Lanza FL. A review of gastric ulcer and gastroduodenal injury in normal volunteers receiving aspirin and other non-steroidal anti-inflammatory drugs. Scand J Gastroenterol 1989:24(suppl 163):24-31.

80 Katz N. Coxibs: evolving role in pain management. Semin Arthritis Rheum 2003;32(suppl): 15-24.

81 Rahme E, Joseph L, Kong SX, Watson DJ, Pellissier JM, LeLorier J. Gastrointestinal-related healthcare resource usage associated with a fixed combination of diclofenac and misoprostol versus other NSAIDs. Pharmacoeconomics 2001;19:577-88.

82 Medina Santillan R, Reyes Garcia G, Mateos Garcia E. Prevention of gastroduodenal injury induced by NSAIDs with low-dose misoprostol. Proc West Pharmacol Soc 1999;42:33-4.

83 Nelson R. Coxibs not cost-effective for arthritis in most patients. Lancet 2003;361:1796.

84 Laine L. Coxibs were not cost-effective for arthritis pain in patients with average risk for ulcer complications. ACP Journal Club 2003;139:53. 